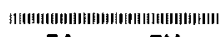

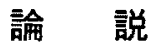

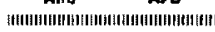

\title{
低合金鋼における $\mathrm{Nb}$ 炭窒化物の生成挙動
}

鈴木寿穂*，森 広司*

\author{
Behavior of Formation of Large-sized $\mathrm{Nb}(\mathrm{C}, \mathrm{N})$ Particles \\ in Nb-bearing Low Alloy Steel
}

Toshio Suzuki and Hiroshi Mori

\begin{abstract}
Synopsis
An addition of niobium to steels is generally available for keeping the austenite grains fine and controlling abnormal grain growth at high temperature. However, it sometimes occurs the formation of large-sized niobium carbonitrides in the center of ingot. This formation of large-sized $\mathrm{Nb}(\mathrm{C}, \mathrm{N})$ particles reduces the microalloying effect by niobium and is harmful to fracture toughness and fatigue strength.

Then three-sized ingots of $50 \mathrm{~kg}, 150 \mathrm{~kg}$ and $1.3 \mathrm{t}$ weight were cast and investigated with Optical Microscope, Electron Probe Micro Analyser (EPMA) and Transmission Electron Microscope (TEM) to study the behaviors of formation of large-sized $\mathrm{Nb}(\mathrm{C}, \mathrm{N})$ particles. Results obtained are as follows;

(1) Large-sized $\mathrm{Nb}(\mathrm{C}, \mathrm{N})$ particles are not formed in molten steels.

(2) They are formed in interdendritic regions during steel solidification.

(3) Those quantities depend on cooling rate during solidification.
\end{abstract}

\section{1. 緒言}

冷間加工を施した低合金鋼に浸炭などの熱処理 を施すと，その冷間加工率が大きい部分任ど，ま た熱処理の温度が高く処理時間が長い場合ほど, オーステナイト結晶粒が局部的に異常成長するこ とがある。これは，結晶粒の再結晶および粒成長 の駆動力となる歪み工ネルギ一や結晶粒界の界面 張力などの分布か鋼材中において不均一な時，ま たは $\mathrm{Al}$ 空化物などの析出物による粒界移動抑止 力が熟処理によって消隇した時に引き起こされ

1994年11月 7 日受付

*大同特殊鋼(㑣)技術開発研究所
る.この現象は, 部品歪み, 鞂性や疲学強度など の機械的強度の低下といった問題の原因になって いる.

これらの对策として，微小で高温域でも安定な $\mathrm{Nb}, \mathrm{Ti}, \mathrm{V}$ などの炭窒化物粒子を鋼中に均一に分 布させることによって，粒界の移動を抑制し，結 晶粒の成長を遅らせる（ピン止めする）方法が広 く用いられている。

$\mathrm{Nb}$ はこの pinning 効果を発揮する有力な結晶 粒微細化元素の 1 つであるが, 凝固時に偏析しや すく，また $\mathrm{Nb}$ 含有鎆は数十 $\mu \mathrm{m} の$ 共晶状の大型 $\mathrm{Nb}(\mathrm{C}, \mathrm{N})$ 晶出物が発生する゙といった問題を抱 之ている，大型 $\mathrm{Nb}(\mathrm{C}, \mathrm{N})$ 晶出物の生成は， $\mathrm{Nb}$ の結晶䊀粗大化抑制効果を消失させ，機㭜的強度 
を大きく低下させることが知られておりり，大型 炭空化物を固溶させるための長時間熱处理は実用 的でないことから， $\mathrm{Nb}$ 添加鋼の坟造においては 大型 $\mathrm{Nb}(\mathrm{C}, \mathrm{N})$ 晶出物の生成を防止することが 重要な課題である.

そこで，各種実験を行い Nb 添加鋼における大 型 $\mathrm{Nb}$ 炭窒化物の生成挙動を調查した。

\section{2. 調查方 法}

\section{1 供試銅塊の搂造}

今回，浸炭処理鋼の最も一般的な鋼種である $\mathrm{SCr} 420$ にb を添加した供試鋼塊を製造し， Nb

(C, N) 晶出物の生成状況を調查した。溶解は50 $\mathrm{kg}$ 高周波大気誘導炉, $150 \mathrm{~kg}$ 高周波真然誘導炬, 4t 電気炉で行い，それぞれ所定の成分に調整した 後に, $50 \mathrm{~kg}$ (上注き法)，150kg (上注ぎ法)，1.3 t（下注き法）鋼塊用の鋳型に鋳込んだ. Table 1
に供試鋏の化学成分, Table 2 に鋳型形状を示寸.

\section{2 溶鋼中晶出物の調查}

溶製段階一鋳型内での唱出物の生成状況を調查 するため，50kg 高周波大気誘導炉では溶鋼中に $\mathrm{Nb}$ を添加した直後（溶鋼温度は1883K）ちよU゙ $\mathrm{Nb}$ 添加後30分保持した後（溶鋼温度は1908K）の 炉内から，また1.3t 鋼塊製造時は錆込み前の取鍋 内 (溶釾温度は $1845 \mathrm{~K})$ および鍀込み後凝固完了前 の鋳型内から，溶鎆分析用吸引サンプル（中9 $\mathrm{mm} \times 100 \mathrm{~mm}$ ）を採取した．サンプルは採取直後 に水冷し，1サンブルから 3 個のミクロ組織観察 用試料を作成して, 光学顕微鏡（倍率：400倍）に よる晶出物の観察を行った。

\section{3 鋼塊内生成物（晶出物）の調查}

晶出物の定量調查としては, 鋳造後の各鋼塊 Middle 部の表層一中心部からミクロ組織観察用 のサンプルを切り出し, 被検面 $: 10 \mathrm{~mm} \times 10 \mathrm{~mm}$

Table 1. Chemical compositions (mass \%).

\begin{tabular}{c|c|c|c|c|c|c|c|c}
\hline No. & $\mathrm{C}$ & $\mathrm{Si}$ & $\mathrm{Mn}$ & $\mathrm{S}$ & $\mathrm{Cr}$ & $\mathrm{Nb}$ & $\mathrm{N}$ & Ingot $(\mathrm{kg})$ \\
\hline 1 & 0.218 & 0.16 & 0.87 & 0.020 & 1.25 & 0.029 & 0.020 & 50 \\
\hline 2 & 0.210 & 0.20 & 0.80 & 0.003 & 1.01 & 0.035 & 0.020 & 50 \\
\hline 3 & 0.197 & 0.19 & 0.75 & 0.016 & 1.07 & 0.083 & 0.025 & 50 \\
\hline 4 & 0.210 & 0.24 & 0.80 & 0.018 & 1.17 & 0.100 & 0.008 & 50 \\
\hline 5 & 0.200 & 0.23 & 0.78 & 0.018 & 1.05 & 0.170 & 0.017 & 50 \\
\hline 6 & 0.199 & 0.14 & 0.79 & 0.018 & 1.12 & 0.195 & 0.030 & 50 \\
\hline 7 & 0.220 & 0.15 & 0.79 & 0.026 & 1.11 & 0.280 & 0.009 & 50 \\
\hline 8 & 0.210 & 0.23 & 0.87 & 0.019 & 1.13 & 0.330 & 0.008 & 50 \\
\hline 9 & 0.200 & 0.21 & 0.87 & 0.017 & 1.06 & 0.320 & 0.019 & 50 \\
\hline 10 & 0.200 & 0.19 & 0.78 & 0.017 & 1.22 & 0.320 & 0.025 & 50 \\
\hline 11 & 0.200 & 0.20 & 0.78 & 0.002 & 1.01 & 0.025 & 0.021 & 150 \\
\hline 12 & 0.199 & 0.27 & 0.84 & 0.016 & 1.00 & 0.030 & 0.024 & 1300 \\
\hline
\end{tabular}

Table 2. Dimensions of ingots mold.

\begin{tabular}{c|c|c|c|c|c}
\hline \multirow{2}{*}{ Mold } & \multirow{2}{*}{$\begin{array}{c}\text { Shape of } \\
\text { cross section }\end{array}$} & $\begin{array}{c}\text { Ingot weight } \\
(\mathrm{kg})\end{array}$ & \multicolumn{2}{|c|}{ Size of ingot $(\mathrm{mm})$} & \multirow{2}{*}{$\begin{array}{c}\text { Height } \\
(\mathrm{mm})\end{array}$} \\
\cline { 3 - 5 } & & Top & Bottom & \\
\hline 13A & $\square$ & 1300 & 435 & 319 & 1215 \\
$\mathrm{A13}$ & 0 & 150 & 189 & 169 & 730 \\
$\mathrm{~A} 05$ & 0 & 50 & 150 & 125 & 380 \\
\hline
\end{tabular}


の試料を作成した後，光学顕微鏡による晶出物観 察とともに画像処理装置（倍率：400倍）を用いて その全域における晶出物面積率を測定した.

また観察された晶出物を EPMA（X 線マイクロ アナライザー)によって定性分析を行い $\mathrm{Nb}, \mathrm{C}$, $\mathrm{N}$ などの分布状況を調查した.

\section{4 鋼塊内生成物の成長挙動調查}

$1.3 \mathrm{t}$ 鋼塊内で観察された数十 $\mu \mathrm{m}$ の生成物（後 述する）が凝固後の冷却過程で発生する可能性が あるか調查するため, 生成物の少なかった $50 \mathrm{~kg}$ 鋼 塊からサンプルを切り出して1073 1373Kの各 温度で10時間保持・水冷後, 抽出レプリカ試料を 作成してTEM（透過型電子顕微鏡）観察を行っ た.またランタムに15000倍の倍率で10視野写真撮 影し，その観察視野内における Nb (C, N) と推 定される生成物の面積率および平均粒子径を画像 処理装置を用いて測定した。

\section{3. 調查および解析結果}

\section{1 溶鋼中における晶出物}

$1.3 \mathrm{t}$ 鋼塊 Middle 部の中心部に生成した大型晶 出物を Fig. 1 に示す．また浴鋼中から採取したサ ンプルの代表例として，1.3t 鋼塊製造時に鋳型内 から採取した溶鋼分析用吸引サンプルの光学顕微

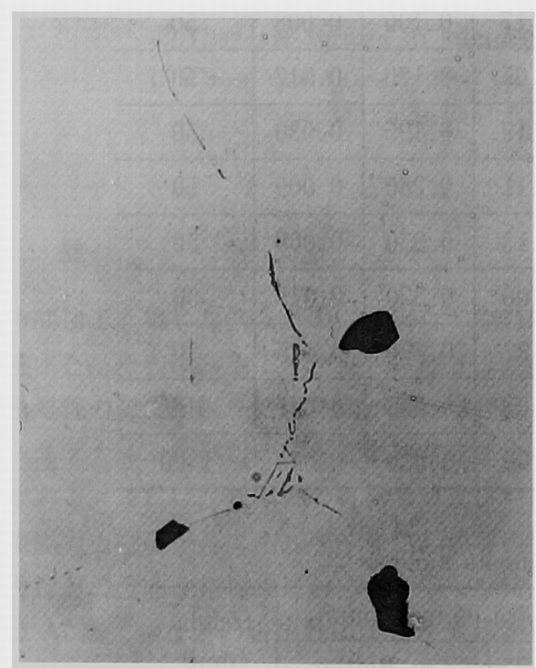

Fig. 1. Microstructure of eutectic $\mathrm{Nb}(\mathrm{C}, \mathrm{N})$ in $1.3 \mathrm{t}$ ingot.

$50 \mu \mathrm{m}$
鏡（倍率：400倍）による観察結果を Fig. 2に示 す. Fig 1に示したような大型の晶出物は観察さ れず, MnS と推定される微小な球状晶出物が若干 見られる程度であった。

一般的に Nb 添加鋼で問題となる大型晶出物は 数十 $\mu \mathrm{m}$ のサイズで共晶状に生成しているが，そ れらの晶出物が溶鋼サンプル中に確認できなかっ たことは, 晶出物の生成時期がサンプル採取以降 の凝固過程であることを示唆している.

溶鉄中における $\mathrm{Nb}$ と $\mathrm{C}, \mathrm{Nb}$ と $\mathrm{N}$ の平衡関係 は，不破ら ${ }^{3)}$ ，森田ら 告されている.

$$
\begin{aligned}
& \underline{\mathrm{Nb}}+\underline{\mathrm{C}} \text { (sat) }=\mathrm{NbC}(\mathrm{s}) \\
& \log [\% \mathrm{Nb}][\% \mathrm{C}] \text { sat }=-4,840 / T+3.73
\end{aligned}
$$

$\underline{\mathrm{Nb}}+\underline{\mathrm{N}}=\mathrm{NbN}(\mathrm{s})$

$\log a_{\mathrm{Nb}} \cdot a_{\mathrm{N}}=-11,100 / T+5.78$

(2)，(4)式加ら添加元素の相互作用5を考虑した としても, Fig. 3, Fig. 4 に示したように溶鉄中の $\mathrm{Nb}, \mathrm{C}, \mathrm{N}$ の溶解度は十分大きく, Nb, C, N は 溶鋼中に溶けこみ, $\mathrm{Nb}$ 宸化物, $\mathrm{Nb}$ 窒化物は晶出 しないと考えられる.

すなわち前述した溶鋼サンプルの観察結果と良 い対応を示している。

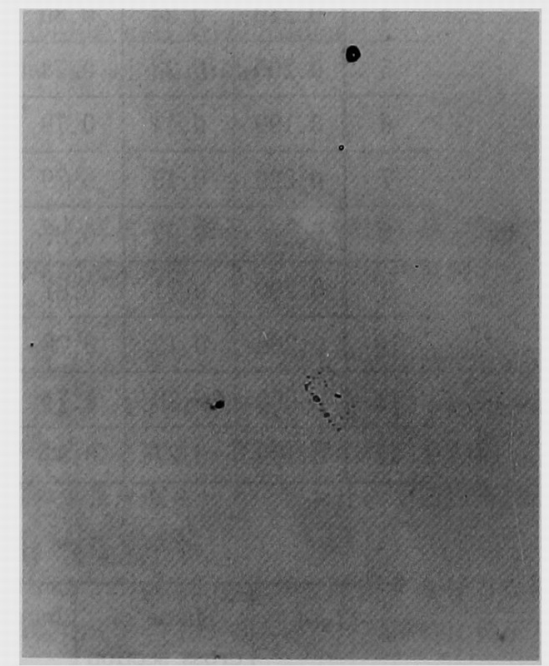

Fig. 2. Microstructure of molten steel sampled from mold during casting.

$50 \mu \mathrm{m}$ 


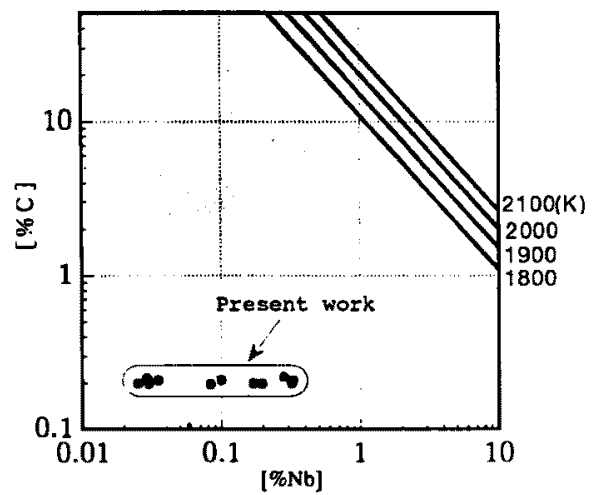

Fig. 3. Effect of niobium on solubility of carbon for reaction $\mathrm{NbC}(\mathrm{s})=\underline{\mathrm{Nb}}+\underline{\mathrm{C}}$.

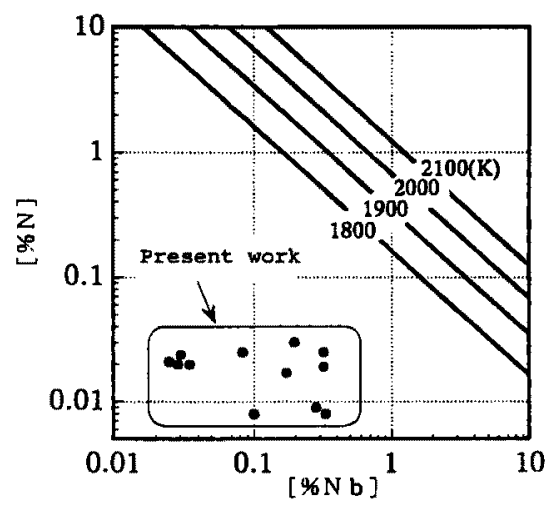

Fig. 4. Effect of niobium on solubility of nitrogen for reaction $\mathrm{NbN}(\mathrm{s})=\underline{\mathrm{Nb}}+\underline{\mathrm{N}}$.

\section{2 大型晶出物の生成状況}

\subsection{1 大型晶出物の組成}

Fig. $5 に 1.3 \mathrm{t}$ 堸塊 Middle 部の中心部に生成し た大型晶出物の EPMAによる mapping 像の一 例を示す.解析結果の要点は以下のとおりである.

(1) $\mathrm{Nb}$ が観察面中央で 3 方向から交差している のと对応するように C，Nもはは同様の分布を示 しており，晶出物は $\mathrm{Nb}(\mathrm{C}, \mathrm{N})$ と推定される. (2) $\mathrm{Al}$ は観察視野内において偏析などは見られ ずほほ均一な分布をしている。

(3) Crは Nb，C，Nの周辺部において濃化が認 められる。

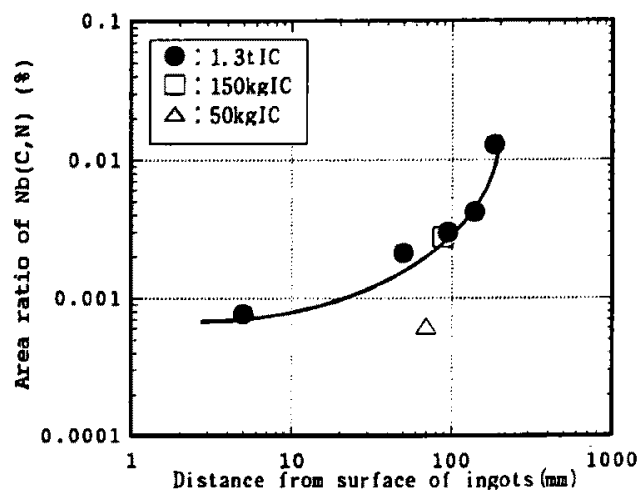

Fig. 6. Relation between area ratio of eutectic $\mathrm{Nb}(\mathrm{C}, \mathrm{N})$ and distance from surface of ingots.

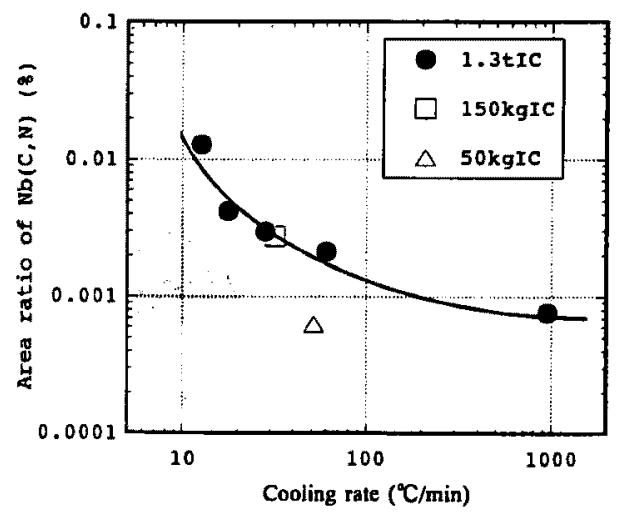

Fig. 7. Relation between area ratio of eutectic $\mathrm{Nb}(\mathrm{C}, \mathrm{N})$ and cooling rate.

\section{2 .2 鋼塊形状別晶出物の分布}

Fig. 6 に $50 \mathrm{~kg}, 150 \mathrm{~kg}, 1.3 \mathrm{t}$ の各種鋁塊 Middle 部における表層からの $\mathrm{Nb}(\mathrm{C}, \mathrm{N})$ 晶出物面積率 を光学顕微鏡およじ画像処理装固（倍率：400倍） を用いて測定した結果を示す. $1.3 \mathrm{t}$ 鋼塊の場合, $\mathrm{Nb}(\mathrm{C}, \mathrm{N})$ 晶出物は鋼塊中心部になるほど多く 生成しているのがかかる。

次に，晶出物の面積率を求めた同一試料の凝固 組織から 2 次デンドライトアームスペーシングを 求め, 鈴木らの式和䞄出した各部位における 固液共存域 (凝固温度範囲) の平均冷却速度と $\mathrm{Nb}$ $(\mathrm{C}, \mathrm{N})$ 晶出物面楥率との関係を求めた，その結 果を Fig. 7 に示す. $\mathrm{Nb}(\mathrm{C}, \mathrm{N})$ 晶出物量は固液 


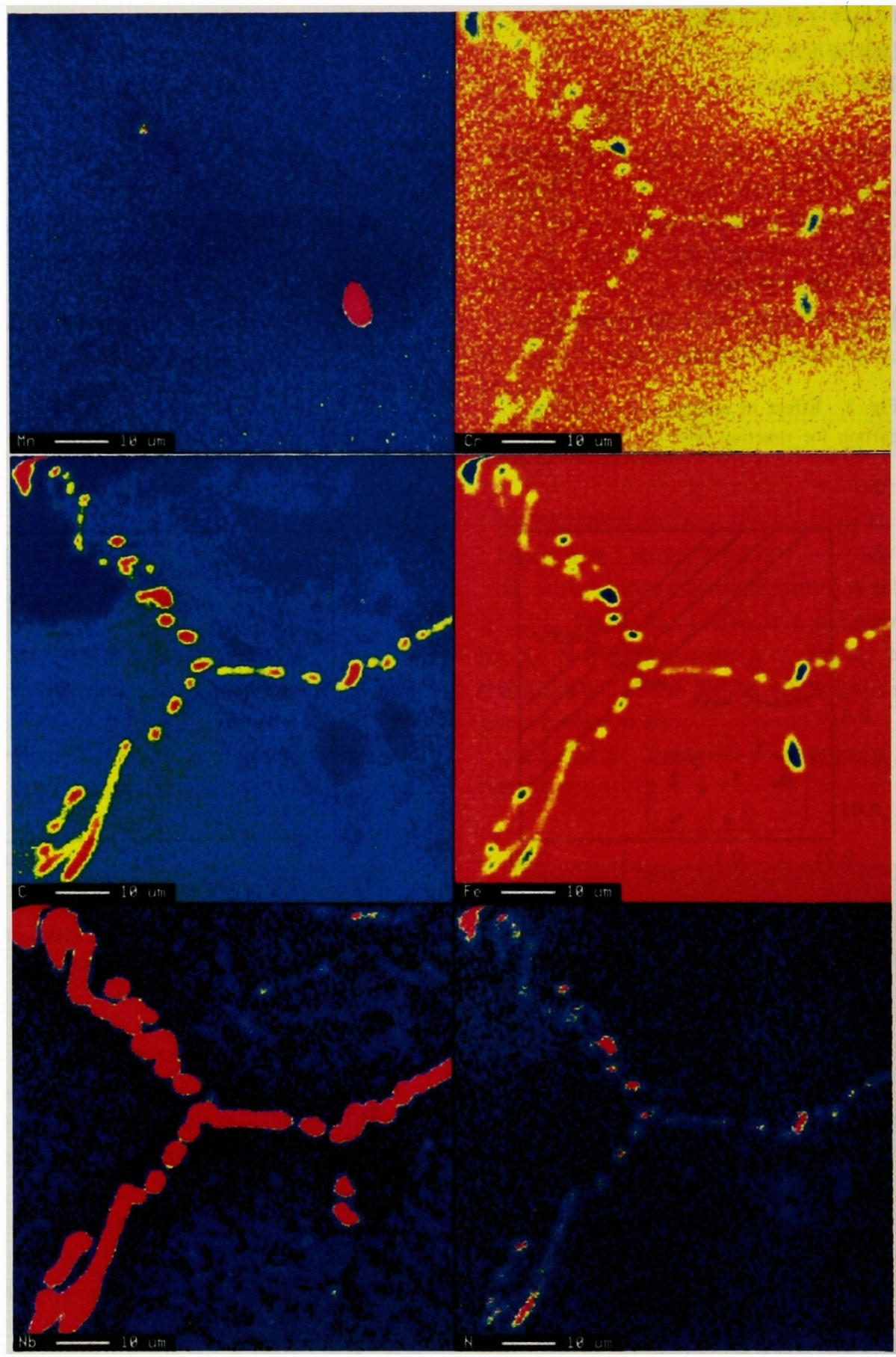

Fig. 5. EPMA images of eutectic Nb $(C, N)$. 
共存域の冷却速度に依存していることがわかる．

すなわち, $\mathrm{Nb}(\mathrm{C}, \mathrm{N})$ 晶出物量を低減するた めには凝固時の冷却速度が重要なポイントの一つ となる。

\section{$3.3 \mathrm{Nb}$ 炭窒化物の成長挙動}

$\mathrm{Nb}$ 崖窒化物の分布及び形状は結晶粒粗大化抑 制に大きく影響し，鋼材の諸特性を左右する重要 な因子の一つである. Nb 炭窒化物の析出挙動に 及ぼす錄造後の熱履歴およひ加工の影響に関する 研究は，今までにもいくつか報告されている7)11) が，本研究と同一成分系の鋼種で調查・研究した 事例はない。そこで, 1.3t 鋼塊で観察された大型 生成物の起源を推定するため，本供試鋼を用いて $\mathrm{Nb}$ 㞸窒化物の成長挙動を調查した。

Fig. 8 に䤻放しままの $50 \mathrm{~kg}$ 鋼塊中心部に存在 する生成物を TEM (透過型電子顕微鏡) で観察し た結果を示す. $\mathrm{Nb}(\mathrm{C}, \mathrm{N})$ は黒く球状に, AlN は 黒く角形に析出しており，灰色に見えるのはセメ ンタイトである、いずれにしろ Nb（C，N）は非 常に微細（数十 nmのオーター）で1.3t 鋼塊で観 察されたような数十 $\mu \mathrm{m}$ の大型の $\mathrm{Nb}(\mathrm{C}, \mathrm{N})$ は 生成していない。

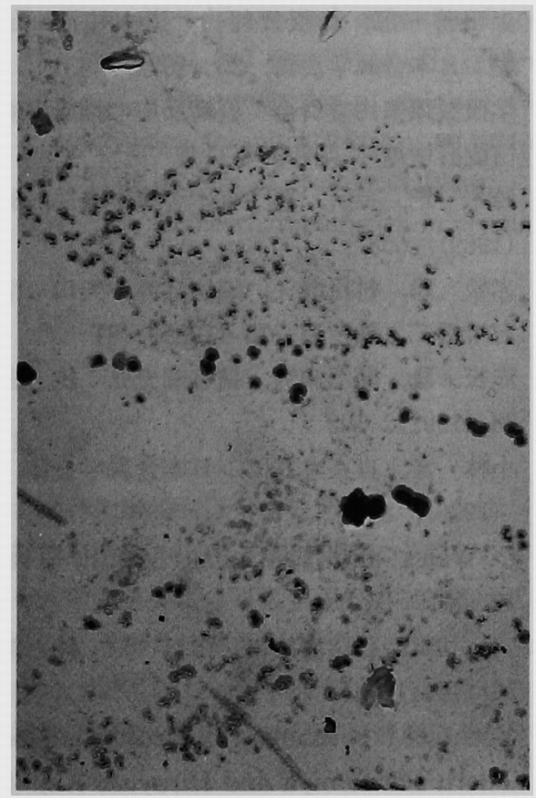

Fig. 8. Micrograph of $\mathrm{Nb}(\mathrm{C}, \mathrm{N})$ precipitates $\left(\times 15,000 \times \frac{3}{4}\right)$. そこで50kg 鋼塊から切り出したサンプルを 1073 1373K の各温度で10時間保持・水冷して, $\mathrm{Nb}$ (C，N) の成長挙動を調查した. 熱処理後の 試料は TEM で観察し， Nb (C,N) と推定され る生成物の面積率および平均粒子径を画像処理装 置を用いて測定した。

Fig. 9 に Nb (C, N) の面積率と保持温度の関 係, Fig. 10 に Nb (C, N) の平均粒子径と保持温 度の関係を示す。高温熱処理により $\mathrm{Nb}(C, N)$ の顕著な成長は認められず, 非常に安定であるこ とがわかる。

以上より，鋼塊内で観察された大型の $\mathrm{Nb}$ (C, N) は凝固後の固相からの析出物ではなく, 凝固過 程で固一液相間における溶質元素の再分配に伴う 濃化溶鋼から晶出した生成物と考えられる。

\section{4. 考槡}

\section{$4.1 \mathrm{Nb}(\mathrm{C}, \mathrm{N})$ 晶出の冷却速度依存性に つい}

Fig.7に示したように $\mathrm{Nb}(\mathrm{C}, \mathrm{N})$ の晶出量は固 液共存域の平均冾却速度の遅い部分で影著に增加 している:これは, 晶出の機構が凝固時の溶質の

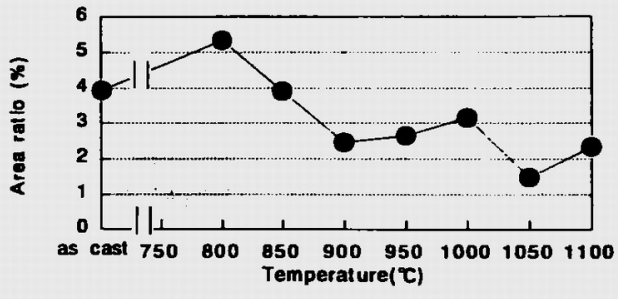

Fig. 9. Relation between area ratio of $\mathrm{Nb}$ (C, N) precipitates and aging temperature.

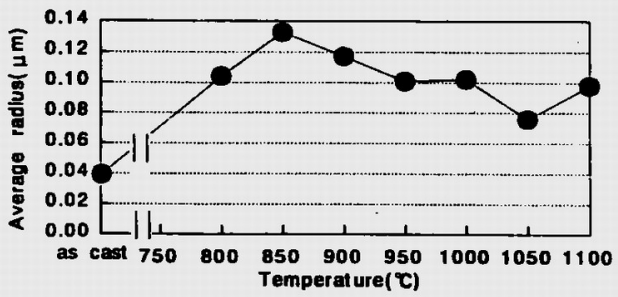

Fig. 10. Relation between average radius of $\mathrm{Nb}(\mathrm{C}, \mathrm{N})$ precipitates and aging temperature. 


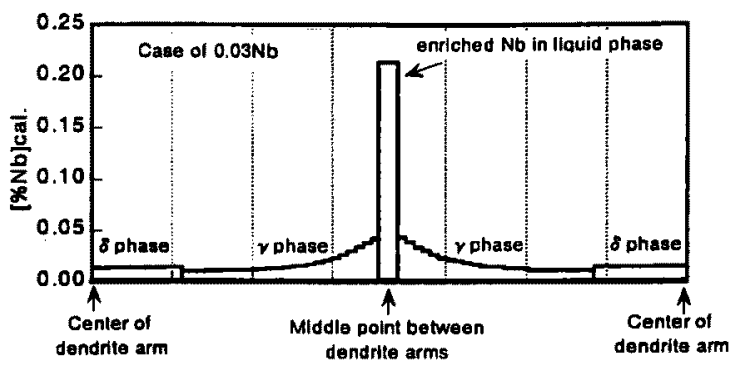

Fig. 11. Calculation of $\mathrm{Nb}$ solute enrichment.

濃化現象やミクロ凝固組織と梁く関連しているこ とを示唆している.すなかち, 平均冷却速度が暒 い場合，デンドライトアーム間隔が大きくなり、 デンドライト樹間での漕化現象が助長され，最䅂 凝固部においては溶解度以上に Nbなどが浱化し て昆出物が形成されるものと考之られる。 そこで，凝固過程における溶質元素の濼化現象 について検討した.

\section{2 凝固過程における溶質元秦の再分配}

Fig.11にUeshima ら ${ }^{12)}$ と同粎の手法を用い て，溶質元素の再分配および拡散を考虑して，直 接差分法によって計算した Nbのデンドライト樹 間における灣化挙動を示す，同困は凝固直前の様 子を示しており，Nbが最終凝固部であるデンド ライトアームの中間点において著しく潭化される 可能性のあることがわかる.

このような濃化はマク口偏析部や凝固時に溶鋼 供給が不十分なために洗浄効果の得られなかった デンドライト樹間部などにおいて発生しやすく， ミクロ偏析として鋼塊の中心部に多く観察され る. また，濃化の程度は凝固組織に大きく影響さ れると考之られるので、凝固組織を微細化するこ とによって低減できる可能性がある。

\section{5. ま と め}

$\mathrm{Nb}$ 添加鋼において，Nb (C，N) の形成される 時期・条件について検討した，得られた結果を要 粎すると次のようになる。

(1)溶製過程および錆型内から探取したサンプル 中には大型の $\mathrm{Nb}(\mathrm{C} ， \mathrm{~N})$ は観察されなかった。

(2)大型の $\mathrm{Nb}(C, N)$ の近傍で $\mathrm{Cr}$ などの浱化が 認められ， $\mathrm{Nb}(\mathrm{C}, \mathrm{N})$ 生成量が煶固温度範围で の冷却速度に依存していることから， Nb(C，N)
は凝固時にデンドライト樹間に晶出したと考えら れる.

(3)大型の $\mathrm{Nb}(\mathrm{C}, \mathrm{N})$ の晶出量を低減するには 凝固時の冷却速度を上げる必要がある。

（文 献）

1）山田人久, 桜井 隆, 竹之内朋夫, 岩波義幸: 鉄と鋼，73 (1987)， 107

2) N. P. Lyakishev, N. A. Tulin and Yu. L. Pliner: Niobium in Steels and Alloys (1985), CBMM

3）不破 鿆, 日野光元, 野間文雄: 学捙第19委 員会, No.10131（昭和53年 9 月）

4）森田善一郎，蜂須賀邦夫，岩永咗治，足立 彰：日本金属学会誌, 35 (1971)，831

5）学振製鋼第19委貝会：製鋼反応の推奖平衡值 (改訂増補)，昭和59年11月

6）鈴木 章, 煨岡 豊：日本金属学会誌，33 (1969), 658

7）赤松 䧔，村松義一，瀨沼武秀，矢田 浩, 石川信二 : 鉄と鋼, 75 (1989), 81

8）赤松 聡, 瀬沼武秀, 長谷部光弘：鉄と鎆, 78 (1992), 102

9）小林 洋, 自在丸二郎：日本金属学会誌, 40 (1976), 828

10) I. Weiss and J. J. Jonas : Metall. Trans. 10A (1979), 831

11）盛 利貞, 藤田清比古, 山口 紘：鉄と鋼, 50 (1964), 41

12) Yoshiyuki Ueshima, Syuzo Mizoguchi, Tooru Matsumiya and Hiroyuki Kajioka : Metall. Trans. 17B (1986), 845 